\title{
Como o psiquismo humano se torna histórico-cultural? As contribuições da análise saussuriana às teses desenvolvimentais de Vigotski
}

Jean-Paul Bronckart*

Ecaterina Bulea*

* Universidade de Genebra, Faculdade de Psicologia e Ciências da Educação.

\section{RESUMO}

Este artigo discute uma das teses fundamentais da obra de Vigotski: a interiorização e a apropriação da linguagem produziriam uma revolução no sistema psicológico humano, fazendo-o passar de um regime biocomportamental para um regime sócio-histórico. Muito embora aceite a validade dessa tese, o presente artigo problematiza algumas implicações do modo como Vigotski a postula; ou seja, problematiza as consequências da suposição da existência de duas raízes desenvolvimentais disjuntas que se uniriam originando 0 pensamento verbal como uma realidade nova, sócio-histórica. Propondo-se a reforçar e desenvolver a tese vigotskiana, os autores buscam nas teorizações de Saussure sobre o signo linguístico aportes para esclarecer aspectos não claramente evidenciados e não desenvolvidos na obra de Vigotski: i) o papel das interações na formação do pensamento verbal; ii) o estatuto E A ESTRUTURAÇÃo dos signos e das significações; iii) o mecanismo pelo qual o pensamento verbal torna-se sóciohistórico. Para essa tarefa, os autores mobilizam um CORPUS ampliado da obra saussuriana, incluindo as notas manuscritas de Saussure - parte delas descobertas em 1996 - e as notas de E. Constantin relativas ao terceiro curso ministrado por Saussure, desconhecidas pelos redatores do curso de linguística geral.

PALAVRAS-CHAVE

Vigotski. Saussure. Desenvolvimento do psiquismo. Signo linguístico. Pensamento verbal. 


\section{AS TESES DE VIGOTSKI}

Uma das teses fundamentais de Vigotski, desenvolvida particularmente em Pensamento e LINGUAGEM ${ }^{1}$ (1934/1997 - de agora em diante $P$ L), é que a apropriação e a interiorização da linguagem provocam uma verdadeira REVOLUÇÃo no funcionamento psicológico humano. Sob o efeito desses dois processos, o psiquismo da criança - que até esse momento funcionava de acordo com modalidades análogas às das outras espécies animais superiores e que, com isso, se inscrevia na continuidade de um desenvolvimento NATURAL - seria inteiramente reorganizado pelos signos e pelas estruturas de linguagem e passaria a se inscrever agora em um desenvolvimento de ordem SóCIO-HISTÓRICA: em outras palavras, com a apropriação da linguagem, as significações historicamente elaboradas por um grupo social, tais como cristalizadas nas unidades e estruturas de uma língua natural, passariam a ser responsáveis pelo conjunto do funcionamento psicológico humano.

No capítulo 4 de PL (AS RAÍZES GENÉTICAS DO PENSAMENTO E DA LINGUAGEM), Vigotski fundamentou essa tese por meio de um esquema de desenvolvimento em Y.

Em uma primeira etapa da ontogênese humana, observar-se-ia, como no mundo animal, a coexistência de duas raízes de desenvolvimento disjuntas, sendo uma delas qualificada de "estágio pré-verbal da inteligência", e a outra de "estágio pré-intelectual da linguagem". Desse modo, esse esquema equivale a considerar que, antes do aparecimento da linguagem, a criança seguiria em paralelo duas formas de desenvolvimento. A primeira proviria de sua interação, não mediada pela linguagem e pelas relações sociais, com os elementops físicos do mundo: nesse plano, ela construiria suas capacidades de representação dos objetos e das ações tais como Piaget (cf. 1936 e 1937) as descreveu em sua análise do estágio sensório-motor. A segunda forma seria resultado da interação, desta vez mediada pela linguagem e pelos outros instrumentos semióticos, com os parceiros sociais (com os elementos sociais do mundo): nesse plano, a criança construiria capacidades de comunicação (co-ações, protolinguagem) tais como elas foram descritas especialmente nos trabalhos produzidos na escola de Bruner (1973).

A apropriação da linguagem seria resultado da fusão dessas duas raízes,

A edição utilizada pelos autores é a tradução francesa: PENSÉE ET LANGAGe, La Dispute, 1997. No Brasil, o título Pensamento e Linguagem (Martins Fontes, 1987) foi usado inicialmente para a tradução da edição resumida da obra de Vigotski organizada por E. Hanfmann e G. Vakar, nos Estados Unidos. Assim, quando por fim foi realizada a tradução da obra integral diretamente do russo, optou-se por outro título: $A$ CONSTRUÇÃO DO PENSAMENTO E DA LINGUAGEM (Martins Fontes, 2001). O mesmo não aconteceu na tradução do texto integral para outras línguas, como o francês (Nota da revisão técnica). 
tese que possui duas implicações, como salientou Schneuwly (1988). Ela significa, por um lado, que as capacidades de representação passam a ser investidas nas trocas comunicativas; por outro lado, e como corolário, que as representações do mundo anteriormente constituídas (na interação com o mundo físico) passam a ser investidas e reorganizadas pelos significados dos signos da língua natural do círculo próximo: as imagens mentais, que até então constituíam entidades inorganizadas e idiossincráticas, passariam a ser verdadeiras unidades delimitadas, o que permitiria o estabelecimento de operações do pensamento propriamente dito.

Esse processo de fusão pensamento-linguagem foi abordado mais ou menos diretamente por Vigotski no capítulo 7 de PL (O PENSAMENTO E A PALAVRA) em uma argumentação a respeito do estatuto do pensamento consciente, que resumiremos do seguinte modo:

a. Uma crítica das concepções antigas e/ou dominantes, que abordam a linguagem e o pensamento como dois fenômenos separados: ${ }^{2}$

b. A afirmação da necessidade de identificar uma unidade do pensamento verbal como um todo, e a tese segundo a qual esta reside na SIGNIFICAÇÃO da palavra:

(1) [...] a falha metodológica fundamental da imensa maioria das pesquisas sobre o pensamento e a linguagem, falha que é causa da esterilidade desses trabalhos, [é] considerar esses dois processos como dois elementos independentes, autônomos e isolados, cuja reunião externa é a fonte do pensamento verbal com todas as propriedades que lhe são inerentes. (VIGOTSKI, 1997, p. 416)

(2) Encontramos essa unidade básica na significação da palavra, que reflete, sob a forma mais simples, a unidade entre o pensamento e a linguagem.

(VIGOTSKI, 1997, p. 417)

A significação é pois concebida como um fenômeno psíquico único, dependendo ao mesmo tempo e, indissoluvelmente, do pensamento e da linguagem:

(3) Desse modo, a significação da palavra é ao mesmo tempo um fenômeno verbal e um fenômeno intelectual, mas isso não significa, para ela, um pertencimento puramente exterior a dois domínios diferentes da vida psíquica. A significação da palavra é um fenômeno do pensamento somente na medida em que o pensamento está vinculado à palavra e encarnado na palavra - e, inversamente, essa significação é um fenômeno da linguagem somente na medida em que a linguagem está vinculada ao pensamento e em que é esclarecida por este último. A significação é um fenômeno do pensamento ou da linguagem dotada de sentido, é a unidade entre a palavra e o pensamento. (VIGOTSKI, 1997, p. 418)

2 Embora se disponha de uma tradução em português de VIGOSKI (1997), os editores optaram por fazer uma nova tradução (nota da revisão técnica). 
c. A introdução de um argumento decisivo aos olhos de Vigostki, proveniente de suas próprias pesquisas empíricas: as significações se DESENVOLVEM na ontogênese, modificam-se, ou, ainda, são DINÂMICAS. Ora, as concepções anteriores não conseguiam explicar essa dinâmica permanente, pois consideravam que as significações não eram senão produtos de uma associação convencional entre a palavra (entidade sonora) e uma ideia prévia, associação que depois de estabelecida não teria mais qualquer razão para ser modificada:

(4) A descoberta de que as significações da palavra não são imutáveis, constantes, invariáveis, e de que elas se desenvolvem, é uma descoberta capital, que é a única que pode salvar a teoria do pensamento e da linguagem do impasse em que ela se colocou. (VIGOTSKI, 1997, p. 427)

d. A afirmação segundo a qual, para explicar essa dinâmica, é preciso analisar

"o papel funcional da significação da palavra no ato de pensamento" ou

"o funcionamento das significações no curso vivo do pensamento verbal" (VIGOTSKI, 1997, p. 427).

Essa análise chega então a duas constatações:

d.1. A unidade constituída pela significação é da ordem não do objeto, mas sim do PROCESSO, de um movimento permanente:

(5) a relação do pensamento com a palavra é antes de tudo não uma coisa, mas sim um processo, é o movimento do pensamento para a palavra e, inversamente, da palavra para o pensamento [...] O pensamento não se exprime na palavra e sim se realiza nela. Por isso se poderia falar de um devir (de uma unidade do ser e do nãoser) do pensamento na palavra. (VIGOTSKI, 1997, p. 428)

d.2. Esse processo é eminentemente COMPLEXO:

(6) Desde a primeira tentativa um quadro grandioso, de extrema complexidade, se oferece a nós, ele supera pela sutileza de sua arquitetônica todos os esquemas que as mais ricas imaginações dos pesquisadores puderam projetar.

(VIGOTSKI, 1997, p. 428)

(7) A unidade da linguagem é uma unidade complexa, não homogênea.

(VIGOTSKI, 1997, p. 429)

e. Após um longo exame do desenvolvimento da linguagem na criança, em suas dimensões externa e interna (linguagem interior), surgem dois tipos de conclusões:

- uma delas diz respeito ao movimento de elaboração do pensamento verbal: 
(8) No drama vivo do pensamento verbal, o movimento se efetua [do seguinte modo]: do motivo, que provoca o nascimento do pensamento, à atribuição de forma a esse próprio pensamento, à sua mediação na linguagem interior, e depois na significação das palavras exteriorizadas e, por fim, nas falas. (VIGOTSKI, 1997, p. 496)

- a outra se refere ao próprio estatuto do pensamento consciente:

(9) A palavra é, realmente, na consciência, aquilo que, segundo Feuerbach, é absolutamente impossivel para um único homem, mas possivel para dois. Ela éa expressão mais direta da natureza histórica da consciência humana. [...] A palavra dotada de sentido é um microcosmo da consciência humana. (VIGOTSKI, 1997, p. 500)

\section{UMA AVALIAÇÃO DESSAS TESES}

Essa abordagem é fundadora do interacionismo social, ou ao menos do ramo dessa corrente que enfatiza o papel decisivo da linguagem (levando-se em consideração a atividade), e concordamos sem reservas com a sua orientação geral, nesse caso com os dois pontos seguintes:

- o caráter decisivo ou revolucionário da transformação do psiquismo sob o efeito da apropriação/interiorização da linguagem: investido por essa linguagem, o psiquismo humano deixa de estar submetido apenas às modalidades de funcionamento natural e é reorganizado porvalores de ordem sócio-histórica;

- a afirmação da existência de uma verdadeira unidade de pensamento verbal, integralmente psíquico, que é dinâmico, processual e complexo.

Mas essa abordagem também suscita diversos tipos de problemas.

a. Como um de nós sustentou em outro trabalho (cf. BRONCKART, 1997), a tese da existência de duas raízes desenvolvimentais disjuntas deve ser rejeitada, e mais amplamente o teor do capítulo 4 de $P L$ não está à altura do teor do capítulo 7, especialmente porque o primeiro ainda está marcado pela aceitação da validade do paralelismo entre filo- e ontogênese, herdado especialmente de Lévy-Bruhl (1927). No capítulo evocado, havíamos mostrado algumas contradições na descrição dessas duas raízes, algo que não poderemos detalhar aqui. Mas, essencialmente, Vigotski parece subestimar o fato de que, entre o nascimento e a aquisição da linguagem, a criança é integrada a formas de atividades humanas reguladas pela linguagem dos adultos e que essa atividade constitui o quadro que serve de 
mediação para o conjunto de suas interações com o mundo físico, ao mesmo tempo e sob modalidades análogas às de suas interações com o mundo social: por causa disso, nesse período, não pode haver nem construções pré-intelectuais puras, nem construções pré-linguageiras independentes das elaborações cognitivas. Entretanto, embora essa tese seja de algum modo inútil, seu complemento, de acordo com o qual a linguagem humana é, essencialmente, uma fusão dos processos de representação e de comunicação, não deve ser rejeitada em razão disso.

b. Também podem ser observados diversos problemas terminológicos: o termo "pensamento" designa em certos casos processos psíquicos anteriores à aquisição da linguagem e, às vezes, o pensamento verbal consecutivo a essa aquisição; o mesmo é válido para o termo “linguagem”, que ora designa as primeiras formas de interações comunicativas, ora as interações verbais propriamente ditas.

c. Essa questão terminológica remete na verdade ao seguinte problema teórico: o que seriam esse pensamento antes da linguagem e essa linguagem antes do pensamento verbal? A citação 8 dá a entender que haveria, num primeiro momento, a constituição de uma primeira forma de pensamento, que seria, secundariamente, transformada sob o efeito da aquisição da linguagem. Essa análise mantém a compatibilidade com a tese segundo a qual coexistiriam duas formas de pensamento humano, um não semiotizado ou propriamente cognitivo e o outro, semiotizado ou verbalizado. É essa forma de tese que sustenta a distinção entre memória semântica e memória cognitiva, ou que é explorada por certas correntes cognitivistas para afirmar a preeminência do pensamento puro, universal, em relação às formas de pensamento que seriam semiotizadas e socioculturalmente dependentes.

d. Por fim, a citação 9 e a referência a Feuerbach dizem claramente que o pensamento consciente é de ordem histórica e requer interações sociais. Mas é preciso constatar que, nas análises anteriores desse capítulo, não são claramente evidenciados e aprofundados:

- $\quad$ o papel efetivo das interações sociais nesse processo;

- $\quad$ o estatuto dos signos/significações e aquilo que, em sua própria estrutura, explica que eles sejam dinâmicos ou perpetuamente mutáveis;

- nem tampouco, definitivamente, o mecanismo por meio do qual o pensamento consciente se torna sócio-histórico. 


\section{AS CONTRIBUIÇÕES DAS REFLEXÕES SAUSSURIANAS SOBRE O SIGNO}

Acreditamos que as reflexões de Ferdinand de Saussure possam contribuir poderosamente para o esclarecimento dos problemas que acabam de ser evocados, desde que se leve em consideração o cORPUS efetivo de sua obra. Se excetuarmosSeUMEMORIALSOBREOSISTEMAPRIMITIVODASVOGAISNASLÍNGUASINDOEUROPEIAS (1879/1922), Saussure praticamente não publicou nada em vida, e o CURSO DE LINGUÍSTICA GERAL (1916/1975), que o tornou famoso, foi composto com base em anotações de alunos dos cursos epônimos que ele ministrou em Genebra de 1907 a 1911 por dois redatores que não assistiram aos cursos. Esse texto oferece apenas um reflexo ao mesmo tempo parcial e deformado da posição efetiva de Saussure, posição que, no entanto, pode ser reconstituída hoje em dia a partir de novos cadernos de estudantes (cf. CONSTANTIN, 2005) ou de suas múltiplas anotações manuscritas, parte delas recentemente descoberta e publicada nos ECRITS DE LINGUISTIQUE GÉNÉRALE (SAUSSURE, 2002). Estamos envolvidos nesse trabalho de reinterpretação da teoria saussuriana efetiva com um conjunto de colegas linguistas (cf. BRONCKART, BULEA E BOTA, 2010).

Note-se, em primeiro lugar, que as propostasteóricas deSaussure se fundamentam em um impressionante trabalho empírico anterior sobre a comparação de múltiplas línguas distribuídas no espaço e no tempo; esse trabalho evidenciou a permanência das mudanças que atingem tanto as palavras como as ideias que elas veiculam e a relação de significação entre esses dois polos.

Observe-se, em segundo lugar, que Saussure dirigia às correntes linguísticas anteriores uma crítica análoga à que Vigotski dirigia aos seus predecessores: o que este último qualificava de posição associacionista era qualificado por Saussure de posição convencionalista simples, concebendo a língua como uma "nomenclatura", isto é, como um conjunto de termos que remetem às coisas, tal como estas últimas se apresentam e são organizadas no mundo. Para os dois autores, concepções desse tipo não permitiam compreender por que os signos das línguas se transformam permanentemente e, além disso, elas pareciam ignorar a dimensão integralmente psíquica dos signos, que Saussure ${ }^{3}$ apresentava do seguinte modo: 4

(10) "A terceira [maneira de representar a palavra] é compreender que a palavra, não mais que seu sentido, não existe fora da consciência que temos dela, ou que queremos ter a cada momento. Estamos muito longe aqui de querer fazer metafisica neste caso.” (SAUSSURE, 2002, p. 83)

3 Todos os excertos das obras de Saussure e dos demais trabalhos citados foram traduzidos por Nicolás Campanário, com revisão técnica de Maurício Érnica (nota da revisão técnica).

4 Nas citações, os trechos que não estão em itálico expressam ênfase dos autores citados, e negritos,representam nossa ênfase.

cadernoscenpec | São Paulo | v.1 | n.1 | p. 147-166 | dez. 2011 
O procedimento de Sassure passou então a ser o de compreender o que é um SIGNO em geral e um SIGNO VERBAL em particular. Reconstituiremos a seguir sua análise em seis etapas, que foram apresentadas mais detalhadamente por um de nós (cf. BULEA, 2005, 2006, 2010).

\subsection{O DUPLO CARÁTER DAS ENTIDADES SONORAS}

Em seus trabalhos anteriores de fonologia, Saussure salientara, por um lado, que as produções sonoras comportam dimensões físicas e fisiológicas acessíveis. Mas ele também observara que, em seu funcionamento linguageiro efetivo, as produções sonoras não podiam ser reduzidas apenas a essa dimensão material; ele ressaltara, mais precisamente, que sua acessibilidade direta não deveria ocultar o fato de que, ao mesmo tempo, na medida em que são proferidos e percebidos pelos humanos, os sons comportam necessariamente uma dimensão de IMPRESSÃO ACÚSTICA, não analisável em si mesma, e por essa razão não DIZEM RESPEITO ESPECIFICAMENTE AO ESTUDO FONOLÓGICO. ${ }^{5}$

(11) Trata-se de observar o mecanismo por meio do qual cada espécie de som é produzida. Além do lado fonatório, há um lado acústico que também entra na fisiologia. Mas é uma coisa (a impressão acústica) que não faz parte do estudo

fonológico. Ela não pode ser analisada [...] Poder-se-ia pensar que os sons são a primeira parte da linguística. A língua é um sistema que corre sobre impressões acústicas inanalisâveis (diferença entre fe $b$ ). Ora, a análise <fonatória > disso não interessa ao linguista. (CONSTANTIN, 2005, p. 151-154)

Essa impressão acústica, que posteriormente será qualificada de IMAGEM ACÚSTICA, é propriamente PSÍQUICA (o que, aliás, constitui a razão de sua inacessibilidade direta): ela procede de traços ou de "marcas" que os humanos possuem e/ou guardam das produções sonoras, NA PRESENÇA OU NA AUSÊNCIA de toda proferição efetiva. Ela SE constitui como uma SEPARAÇÃO das propriedades de sua base empírica e desse modo é dotada de uma existência outra, IMATERIAL, que possui notadamente a propriedade de transcender tanto à singularidade da execução de cada ato fônico como ao caráter irredutivelmente efêmero de suas propriedades estritamente físicas.

Além disso, essa imagem acústica não se TORNA signo senão sob a condição de que uma ideia the seja associada e nas condições em que a ideia é associada a ela. Isso produziu a célebre fórmula do CURSO DE LINGUÍSTICA GERAL:

(12) "O signo linguístico não une uma coisa e um nome, mas sim um conceito e uma imagem acústica. Esta última não é o som material, coisa puramente física, mas a impressão psíquica desse som, a representação que nos é fornecida pelo testemunho de nossos sentidos; ela é sensorial, e caso cheguemos a qualificá-la de 'material', fazemos isso apenas nesse sentido e por oposição ao outro termo da associação, o conceito, geralmente mais abstrato.” (SAUSSURE, 1975, p. 98)

Em vários manuscritos de Saussure, o termo "fonologia" designa de fato a disciplina que atualmente é qualificada de fonética (análise das propriedades físicas dos sons, abstraindo-se seu valor distintivo no quadro de uma língua natural). 
Com base nisso, portanto, Saussure dissocia, na vertente sonora dos signos, por um lado a FIGURA VOCAL, que designa a dimensão material ou perceptível de sons ou palavras, e a IMAGEM ACÚSTICA, como forma que entra na composição do signo, desde que lhe seja associada uma ideia:

(13) "É falso (e impraticável) opor a forma e o sentido. É correto, em compensação, opor a figura vocal, por um lado, e a forma-sentido, por outro." (SAUSSURE, 2002, p. 17)

Essa análise implica que o que funciona semioticamente na vertente sonora é uma imagem psíquica que se separou da materialidade dos sons e que esta não se constrói senão dentro e por sua associação a uma significação.

\subsection{O CARÁTER RADICALMENTE ESPECÍFICO OU SEMIÓTICO DAS SIGNIFICAÇÕES}

Nessa vertente do sentido, Saussure contesta em primeiro lugar que os CONTEÚDOS DOS SIGNOS POSSAM SER DADOS DEANTEMÃO, no nível dos objetos ou referentes existentes no mundo. E ele também contesta, por conseguinte, que a estruturação dos signos se efetue de acordo com a dos objetos aos quais eles remetem. Em outras palavras, ele rejeita TODA BASE OU TODO FUNDAMENTO EXTERNO (mundano) para e durante a constituição-configuração dos signos:

(14) Primeiramente o objeto, depois o signo; portanto (o que jamais negaremos)

base exterior dada ao signo. [...] Certamente é lastimável que se comece a misturar a ele, como elemento primordial, esse dado dos objetos designados, os quais não formam nenhum elemento qualquer. (SAUSSURE, 2002, p. 230-231)

Mas ele contesta igualmente que as estruturas de pensamento condicionem a estruturação dos signos de uma língua:

(15) É falso pensar que haja em algum lugar formas (existentes por si mesmas fora de seu uso) ou em outro lugar ideias (existentes por si mesmas fora de sua representação). (SAUSSURE, 2002, p. 31)

De fato, a posição de Saussure sobre esse tema pode ser resumida do seguinte modo: - alguns autores sustentam que existem “ideias” anteriores à sua colocação em um SıGNo, mas em qualquer situação imaginável, se esse for o caso, essas ideias não possuem nada de linguístico; - na verdade, o autor duvida, até mesmo contesta, que verdadeiras “ideias”, na condição de unidades de pensamento distintas, acessíveis e operacionais, possam preexistir aos signos: 
(16) I. Domínio não linguístico do pensamento puro, ou sem signo vocal, e fora do signo vocal. É a esse domínio, não importando a que ciência ele estiver vinculado, que deve ser relegada toda espécie de categoria absoluta da ideia, se ela for realmente considerada como absoluta, se se pretender, por exemplo, colocar a categoria Sol ou a categoria do FUTURO ou a do SUBSTANTIVO desde que elas sejam consideradas como realmente absolutas e independentes dos signos vocais de uma língua, ou das infinitas variedades de signos quaisquer. (SAUSSURE, 2002, p. 44)

Além disso, assim como as imagens acústicas não são elaboradas senão em sua associação com as significações, essas significações, por sua vez, são entidades psíquicas que não são elaboradas senão em e por sua associação a uma imagem acústica.

(17) Psicologicamente, o que são nossas ideias quando se faz abstração da língua? Provavelmente elas não existam, ou passem a existir sob uma forma que pode ser qualificada de amorfa. Provavelmente <não $>$ teríamos < segundo filósofos e linguistas > como distinguir <claramente> duas ideias sem o auxílio da língua (lingua interior, naturalmente). Por conseguinte, considerada em si mesma, a massa puramente conceitual de nossas ideias, a massa separada da língua representa uma espécie de nebulosa informe na qual não se poderia distinguir nada desde a origem.

Portanto, de modo recíproco para a língua, as diferentes ideias não representam nada preexistente. Não há: a) ideias que seriam completamente estabelecidas e completamente distintas umas em relação às outras, $b$ ) signos para essas ideias. Mas não há nada distinto no pensamento antes do signo linguístico. Isto é o mais importante. Por outro lado, vale a pena perguntar-se se frente a esse reino de ideias totalmente confuso, o reino do som ofereceria de antemão unidades bem distintas

(considerado em si mesmo fora da ideia). Tampouco há no som unidades bem distintas, circunscritas de antemão. É nesse entremeio que o fato linguístico ocorre

(CONSTANTIN, 2005, p. 285).

Combinada à precedente, essa análise conduz à dessubstancialização radical do signo, e isso em suas duas vertentes. No plano sonoro, não são as figuras vocais (os sons em suas propriedades físicas perceptíveis) que intervêm como tais no signo, mas sim as imagens acústicas extraídas dessas figuras, e que são pois formas psíquicas. No plano das ideias, as significações que se articulam a essas imagens não são condicionadas nem pelas propriedades dos referentes mundanos, nem por unidades ou operações de pensamento que existiriam antes da língua; são formas psíquicas, mas que são particulares ou próprias da ordem semiótica.

\subsection{O SIGNO COMO ENTIDADE PURAMENTE PROCESSUAL}

Os signos não existem, pois, senão como união, como ASSOCIAÇÃo dessas duas formas psíquicas. Essas formas, cujo substrato é heterogêneo (sonoro e 
ideal), tornam-se homogêneas em e por essa associação; "homogêneas" no sentido em que elas interagem e se constituem em uma unidade dual de outra ordem, precisamente a ordem semiótica. 0 signo é, pois, fundamentalmente, da ordem do PROCESSO, mas não de um processo de correspondência de entidades pré-organizadas: ele é uma espécie de MECANISMO PSÍQUICO de geração de entidades significantes, por associação:

(18) II. Domínio linguístico do pensamento que se torna IDEIA No SIGNo ou da figura vocal que se torna SIGNO NA IDEIA: o que não são duas coisas e sim Uma, contrariamente ao primeiro erro fundamental. É tão literalmente verdadeiro dizer que a palavra é o signo da ideia quanto dizer que a ideia é o signo da palavra; ela o é a cada instante pois sequer é possivel fixar e limitar materialmente uma palavra na frase sem ela. (SAUSSURE, 2002, p. 44-45)

O signo é criação ou emergência de uma nova ordem, que é uma FORMA AUTÔNOMA de reexploração conjunta de dois domínios, um "acoplamento" destes para além de sua heterogeneidade constitutiva; ele é, pois, fundamentalmente ATIVO:

(19) [...] a linguagem não oferece sob nenhuma de suas manifestações uma substância mas tão somente ações combinadas ou isoladas de forças fisiológicas, fisicas, mentais [...]. (SAUSSURE, 2002, p. 197)

Isto implica que o modo de existência coincida com sua perpétua (re)produção; como o “pensamento-som' implica divisões” que rompem a continuidade amorfa, esse processo de discretização é ilimitado e potencialmente reprodutível ao infinito. Saussure dirá que o signo provém de uma atividade incessante.

\subsection{O SIGNO COMO FENÔMENO COMPLEXO}

Saussure introduz essa problemática da complexidade do signo por meio da metáfora da constituição do ar e da água, assim como Vigostki fizera para introduzir a questão da complexidade das unidades de análise da psicologia:

(20) Poder-se-ia comparar a entidade linguística com um corpo químico composto, como a água, na qual há hidrogênio e oxigênio $\left.<\left(\mathrm{H}_{2} \mathrm{O}\right)\right\rangle$. Não há dúvida de que se a química separar os elementos, ela obterá oxigênio e hidrogênio, mas permanecerse-á na ordem química. Pelo contrấrio, caso se decomponha a água linguística <extraindo o hidrogênio ou o oxigênio>, deixar-se-â a ordem linguística < (não haverá mais entidade linguística)>. (CONSTANTIN, 2005, p. 224)

Entretanto, esse tipo de comparação não fornece modelo algum ou analogia que possa ser diretamente explorado na ordem dos signos. Como Saussure se 
apressa em ressaltar, as ordens física ou química PODEM comportar (e de fato comportam) tanto entidades simples dotadas de uma estruturação própria (nitrogênio, oxigênio, hidrogênio) como entidades complexas, provenientes da síntese das primeiras. Mas essa própria diferença evidencia o que constitui uma das características IRREDUTÍVEIS da ordem dos signos: essa ordem possui EXCLUSIVAMENTE entidades complexas e existe unicamente em virtude dessa forma de organização. Mas em que reside essa complexidade?

Na vertente sonora, toda forma deve de fato ser considerada como proveniente de um ENGENDRAMENTO, isto é, como procedente de um trabalho de diferenciação APLICADO ÀS FIGURAS VOCAIS. Mais precisamente, a noção de forma diz respeito a um PROCESSO DE CONTRASTAÇÃO de figuras vocais, ou ainda a um processo de seleção, de identificação e de extração contrastivas de conjuntos de características por meio dos quais essas figuras são efetivamente diferenciadas umas das outras. Na falta desse processo, a figura vocal permanece o que é no plano físico, isto é, uma sequência fônica qualquer ou "vazia"; para que possa se tornar uma entidade de ordem linguística, ela deve ser dotada de uma existência para e na consciência dos sujeitos falantes, isto é, ser experimentada, delimitada ou ainda determinada:

(21) Uma forma é uma figura vocal que é, para a consciência dos sujeitos falantes, determinada, isto é, ao mesmo tempo existente e delimitada. Ela não é nada mais que isso, mas tampouco menos. Ela não possui necessariamente "um sentido" preciso; mas ela é experimentada como algo que é; que, além disso, não seria mais, ou não seria mais a mesma coisa, caso se mudasse qualquer coisa em sua exata configuração. (SAUSSURE, 2002, p. 37)

Nessa primeira abordagem, a noção de forma remete, pois, ao TRATAMENTO PSÍQUICO DISCRIMINATIVO DAS FIGURAS VOCAIS, tal como este é REALIZADO E EXPERIMENTADO PELOS SUJEITOS FALANTES. Mas Saussure destaca, além disso, que esse primeiro processo de diferenciação se realiza conjuntamente à diferenciação das ideias ou do sentido; e que é em virtude desse caráter duplo desse primeiro regime de diferenciação que os produtos que dele resultam se tornam potencialmente associáveis:

(22) Não é possível definir o que é uma forma com o auxílio da figura vocal que ela representa, e menos ainda com a ajuda do sentido que essa figura vocal contém. É-se obrigado a pôr como fato primordial o fato GERAL, COMPLEXO e composto de DOIS FATOS NEGATIVOS: da diferença geral das figuras vocais unida à diferença geral dos sentidos que podem se ligar a elas. (SAUSSURE, 2002, p. 29)

Desse modo, a modalidade de existência dos signos é totalmente particular, 
naquilo que ela é inelutavelmente: - NEGATIVA, isto é, não definível A PRIORI ou em referência a um fundamento externo qualquer; - CORRELATIVA, no sentido em que as formas definem-se umas em relação às outras; - COMPLEXA, uma vez que nem as formas nem os sentidos existem enquanto tais fora de sua associação:

(23) FORMA = Não certa entidade positiva de uma ordem qualquer, e de uma ordem simples; mas a entidade ao mesmo tempo negativa e complexa: resultante (sem nenhuma espécie de base material) da diferença com outras formas COMBINADA com $a$ diferença de significação de outras formas. (SAUSSURE, 2002, p. 36)

Em outras palavras, essa modalidade particular de individuação reside na CODETERMINAÇÃO DAS FORMAS E DOS SENTIDOS EM SUA UNIÃO, o que implica que toda delimitação de entidades é realizada exclusivamente no INTERIOR da ordem semiológica. Por isso, a ordem dos signos não é senão o espaço de coestabelecimento de entidades complexas, cuja unidade não é senão o produto irredutível de TRÊS RELAÇÕES SIMULTANEAMENTE ATIVAS: - as relações diferenciais das formas entre si; - as relações igualmente diferenciais das significações entre si; - por fim, as relações associativas entre formas e significações:

(24) Somos sempre reconduzidos aos quatro termos irredutiveis e às três relações irredutiveis entre eles, que formam um único todo para a mente: (um signo/sua significação $)=($ um signo/e um outro signo $)$ e além disso $=($ uma significação/uma outra significação). [...] Mas na verdade não há na língua nenhuma determinação da ideia ou da forma; não há outra determinação senão a da ideia pela forma e da forma pela ideia. [...] É a isso que chamamos QUATERNIÃO FINAL $e$, considerando os quatro termos em suas relações: a tripla relação irredutível. (SAUSSURE, 2002, p. 39)

Esse “quaternião" integralmente psíquico, também qualificado de "ser quádruplo" (SAUSSURE, 2002, p. 42), que, no entanto, constitui “um único todo para a mente" (IBID., p. 39), é a formulação operacional da solução alternativa que opõe Saussure à dualidade tradicional "forma vs sentido". E caso se admita que esse ser constitui realmente uma única entidade, trata-se então de uma unidade que comporta, como um de seus ingredientes constitutivos, O PRÓPRIO MECANISMO QUE O GERA; isSo o torna um ser instável por natureza, cujas concretizações permanecem frágeis, até mesmo precárias, na medida em que resultam apenas da mobilização de elementos da circunvizinhança semiológica coexistente, que são igualmente frágeis.

\subsection{O SIGNO COMO ENTIDADE VAZIA}


A reflexão precedente conduz então à afirmação de que o signo é uma "essência relativa", que SUA REALIDADE É PURAMENTE RELACIONAL E OPOSITIVA, ou ainda que essa realidade depende da coexistência e das posições recíprocas de formas, de sentidos, ou de signos em sua integralidade:

(25) [...] nunca há nada que possa residir dentro de um termo (como consequência direta de que os símbolos linguísticos não possuem relação com aquilo que eles devem designar), que a é impotente para designar algo sem o auxílio de b, e este tampouco sem o socorro de a; ou que ambos não valem, pois senão devido à sua recíproca diferença. (SAUSSURE, 2002, p. 218)

(26) Não há a forma e uma ideia correspondente; tampouco há a significação e um signo correspondente. Há formas e significações possíveis (de modo algum correspondentes); há, na verdade, apenas diferenças de formas e diferenças de significações; por outro lado, cada uma dessas ordens de diferenças (por conseguinte, de coisas já negativas em si mesmas) existe tão somente como diferença graças à união com a outra. (SAUSSURE, 2002, p. 42-43)

(27) FORMA = Não uma certa entidade positiva de uma ordem qualquer, e de uma ordem simples; mas a entidade ao mesmo tempo negativa e complexa: resultante (sem nenhuma espécie de base material) da diferença com outras formas COMBINADA com a diferença de significação de outras formas. (SAUSSURE, 2002, p. 36)

Levando a sua análise até as últimas consequências, Saussure concluirá que os signos são na verdade ENTIDADES VAZIAS, isto é, entidades cuja própria essência não é constituída nem por elementos físicos (sons ou objetos externos), nem pelas operações cognitivas de um sujeito. Para ele, definitivamente, os signos são fantasmas, "bolhas de sabão":

(28) Nenhum signo é, pois, limitado na soma de ideias positivas que ele é ao mesmo tempo chamado a concentrar apenas em si mesmo; [...] é, pois, algo vão procurar qual é a soma das significações de uma palavra.

(SAUSSURE, 2002, p. 78)

(29) [...] é uma lição diária, para aqueles que estudam, ver que a associação - que às vezes acalentamos - não é senão uma bolha de sabão, talvez nem sequer uma bolha de sabão, que ao menos possui sua unidade física e matemática [...]. (cf. TURPIN, 2003, p. 387-388)

\subsection{A POSITIVIDADE DOS SIGNOS (OU SEU valor) PROVÉM SOMENTE DA HISTÓRIA}

SOCIAL, E OS SIGNOS, PORTANTO, SÃO INTEGRALMENTE SOCIAIS

Da análise precedente, Saussure conclui que os signos estão fundamentados "na própria IRRAZÃO" e que a organização do sistema da língua não é "corrigível ou dirigível pela razão humana":

(30) [...] porque, com efeito, nada mais garante - a partir do momento em que o sistema de signos pertence à coletividade - que seja uma razão interior, uma razão constituída à imagem de nossa razão individual, que continuará a governar a relação entre o signo e a ideia. Como não sabemos mais que força e que lei (forças e lei ou que leis no plural) serão misturadas à vida desse sistema de signos, não podemos saber, adivinhar, precisamente, antes de tê-las estudado, observado mediante um estudo profundamente diferente daquele que consiste em conceber as condições normais ou puramente racionais do signo frente à ideia (de acordo com uma medida racional). (SAUSSURE, 2002, p. 289) 
e. Mas os signos, contudo, possuem uma positividade, ou adquirem um valor, e esse valor provém unicamente do hábito social; ele é produto tão somente das trocas e das interações sociais, em sincronia (nos intercâmbios cotidianos) ou em diacronia:

(31) Uma palavra só existe realmente, e isso de qualquer ponto de vista que se esteja, pela sanção que recebe momento a momento daqueles que a empregam. (SAUSSURE, 2002, p. 83)

(32) - A troca, como única expressão verdadeira de todo movimento na língua. [...] Na troca, a unidade é estabelecida pelo valor ideal, em nome do qual são declarados adequados entre si dois objetos materiais que podem, aliás, ser absolutamente dessemelhantes e, além disso, constantemente renovados em sua substância. Esse é exatamente o caráter de todas as 'mudanças' ou 'movimentos' linguísticos. (SAUSSURE, 2002, p. 60)

O signo e a língua como sistema de signos são, pois, fundamentalmente sociais, ou, em outras palavras, o social é o lugar, ou o meio, de realização da língua: o social é uma propriedade interna da língua, e essa é até mesmo sua única propriedade positiva.

(33) [...] se esse meio da coletividade muda tudo para o sistema de signos, esse meio também é, desde a origem, o local de desenvolvimento para o qual tende o sistema de signos desde o seu nascimento: um sistema de signos é feito propriamente para a coletividade, assim como o barco é feito para o mar. Ele é feito apenas para que vârios ou muitos se entendam e não para que alguém sozinho entenda a si mesmo. Por isso em nenhum momento, contrariamente à aparência, o fenômeno semiológico, qualquer que seja, deixa fora de si o elemento de sua coletividade social: a coletividade social e suas leis são um dos elementos internos e não externos. Esse é o nosso ponto de vista. (SAUSSURE, 2002, p. 289-290)

f. Onde se operam essas trocas, essa atividade social literalmente fabricadora de significações? A resposta de Saussure, totalmente eludida pelos redatores do CURSO DE LINGUíSTICA GERAL, era, no entanto, clara; essas trocas se efetuam somente na atividade de fala, isto é, no discurso.

(34) Todas as modificações, sejam fonéticas, sejam gramaticais (analógicas) se dão exclusivamente no discursivo. Não há nenhum momento em que o sujeito submeta a uma revisão o tesouro mental da língua que ele possui dento de si e crie com a mente descansada novas formas [...] que ele se propõe (promete) 'colocar' em seu próximo discurso. Toda inovação acontece por improvisação, ao falar, e penetra desse modo seja no tesouro íntimo do ouvinte ou no do orador, mas se produz, pois, a respeito da linguagem discursiva. (SAUSSURE, 2002, p. 95)

(35) Somente a linguística, ouso dizer, é vasta. Ela comporta notadamente duas partes: uma que está mais próxima da língua, depósito passivo, e a outra, que está mais próxima da fala, força ativa e origem verdadeira dos fenômenos que depois podem ser percebidos pouco a pouco na outra metade da linguagem.

(SAUSSURE, 2002, p. 273) 
(36) Do lado interno (esfera da língua), nunca há premeditação, nem tampouco meditação, reflexão sobre as formas, fora do ato, da ocasião da fala, salvo uma atividade inconsciente quase passiva, em todo caso não criadora: a atividade de classificação. Quando se diz que tudo aquilo que se produz de novo é criado no momento do discurso, diz-se ao mesmo tempo que tudo acontece no lado social da linguagem. (ENGLER, 1968, p. 384)

g. E é a natureza social da língua que explica seu movimento, seu dinamismo permanente: as línguas mudam porque seus ingredientes são de natureza sócio-histórica, ainda que estejam ancorados no psiquismo dos indivíduos:

(37) [...] o fenômeno sócio-histórico [...] carrega, pois, o turbilhão dos signos para a coluna vertical e impede então que ele seja transformado em um fenômeno fixo ou em uma linguagem convencional, em razão dele ser o resultado incessante da ação social, imposto acima de qualquer escolha. (SAUSSURE, 2002, p. 102)

\section{4. À GUISA DE SÍNTESE}

A concepção vigotskiana do desenvolvimento humano pode ser resumida e simbolizada pela famosa fórmula de PENSAMENTO E LINGUAGEM:

(38) O pensamento da criança [...] depende em seu desenvolvimento do domínio dos meios sociais do pensamento, isto é, depende da linguagem. [Com a emergência do pensamento verbal], o próprio tipo de desenvolvimento se modificou, passando do biológico para o sócio-histórico. (VYGOTSKI, 1997, p. 187)

Oquepretendemosdemonstrarnesta contribuiçãofoiqueaanálise saussuriana do signo fornece todos os elementos necessários para compreender como se efetua essa transformação do biológico no sócio-histórico. Com efeito, de acordo com essa análise, os processos mobilizados na confecção dos signos são processos psíquicos ELEMENTARES (a construção de imagens mentais, a diferenciação e a associação) que Piaget (1992) claramente mostrou serem comuns tanto aos humanos como aos animais. Os processos de construção dos signos situam-se, assim, no prolongamento direto dos processos comuns do vivente: é o aspecto de CONTINUIDADE decorrente da evolução das espécies. Mas, uma vez constituídos, esses signos transformam radicalmente o psiquismo herdado e fazem-no passar, de acordo com a formulação de Vigotski, do regime biocomportamental para o regime sócio-histórico: esse é o aspecto da RUPTURA fundadora da especificidade humana.

O signo é, desse modo, O PRóPRIO LUGAR DA CONTINUIDADE-RUPTURA, e O elemento determinante da ruptura está ligado ao fato de que os processos biologicamente herdados se aplicam não mais apenas a objetos físicos (como 
no mundo animal), mas a OBJETOS SOCIAIS, a esses "pequenos ruídos emitidos pela boca” (de acordo com a expressão de Bloomfield, 1933/1970), que são convencionalmente associados a dimensões da atividade humana. Em outras palavras, os signos possuem a propriedade radicalmente nova na evolução de constituir CRISTALIZAÇÕES PSÍQUICAS DE UNIDADES DE INTERCÂMBIO SOCIAL e é essa socialização do psiquismo que é fundadora do humano.

TRADUÇÃO de Nicolás Campanário REVISÃO TÉCNICA de Maurício Érnica 


\section{How did the human psyche become cultural-historical? The contributions of Saussurian analysis to Vygotski's developmental theories}

ABSTRACT

This article discusses one of the fundamental theories of Vygotski's work: that the interiorization and appropriation of language would cause a revolution in the human psychological system, causing it to go through a bio-behavioral regime to a social-historical regime. Although the validity of this is accepted, this paper presents the problems of some of the implications of how Vygotski postulated it; in other words, it shows the problems regarding the consequences of the supposition that two disjointed developmental roots would be joined by originating in verbal thought as a new socio-historical reality. In proposing to reinforce and develop Vygotski's theory, the authors look to Saussure's theories on the linguistic sign for contributions to clarify aspects that are not clearly seen and developed in Vygotski's work: i) the role of interactions on the formation of verbal thinking; ii) the nature of signs and meanings; iii) the mechanism and structure through which verbal thinking becomes socio-historical thinking. To do this, the authors mobilized a broader CORPUS of Saussure's work, including Saussure's manuscript notes - part of which were discovered in 1996 - and the notes of E. Constantin regarding the third class given by Saussure, which were unknown to the reporters of the general linguistics course.

\section{KEYWORDS}

Vygotski. Saussure. Development of the psyche. Linguistic sign. Verbal thought. 


\section{Referências}

BLOOMFIELD, L. Le LANGAGE. Paris : Payot, 1970. [edição original : 1933].

BRONCKART, J.-P. "Action, discours et rationalisation; l'hypothèse développementale de Vygotsky revisitée”. In: MORO, Ch.; SCHNEUWLY, B.; BROSSART, M. (org). OUTILS ET SIGNES. Perspectives actuelles de la théorie de Vygotsky. Berna: P. Lang, 1997. p. 199-221.

BRONCKART, J.-P.; BULEA, E.; BOTA, C. LE PROJET DE FERDINAND DE SAUSSURE. Genebra: Droz, 2010.

BRUNER, J.S. BEYOND THE INFORMATION GIVEN. Nova York: Norton, 1973.

BULEA, E. “Est-ce ainsi que les signes vivent ?”. TEXTO ! [ON-LINE], [S.I.], v. 10, n. 4, 2005. Disponível em: http://www.revue-texto.net/

BULEA, E. "La nature dynamique des faits langagiers, ou de la « vie » chez Ferdinand de Saussure”. CAHIERS FERDINAND DE SAUSSURE, n. 59, p.5-19, 2006.

BULEA, E. "Le défi épistémologique de la dynamique temporalisée". In: BRONCKART, J.P; BULEA, E.; BOTA, C. LE PROJET DE FERDINAND DE SAUSSURE. Genebra: Droz, 2010. p. 213-235.

CONSTANTIN, E. “Linguistique générale. Cours de M. le professeur F. de Saussure". CaHIERS FERdinand de SAUSSURE, [S.I.], n. 58, p. 71-289, 2005.

ENGLER,R.COURSDELINGUISTIQUEGÉNÉRALE, tomel.Wiesbaden:Harrassowitz,1968.

ENGLER, R. COURS DE LINGUISTIQUE GÉNÉRALE, tome II, APPENDICE. Wiesbaden: Harrassowitz, 1974.

KOMATSU,E.;WOLF,G.PREMIER COURSDELINGUISTIQUEGÉNÉRALE(1907)D'APRÈS LES CAHIERS D’Albert RIEDlinger. Oxford;Tóquio: Pergamon, 1996.

LEVY-BRUHL, L. L’ÂME PRIMITIVE. Paris : Alcan, 1927.

PIAGET, J. LA NAISSANCE DE L'INTELLIGENCE CHEZ L'ENFANT. Neuchâtel: Delachaux et Niestlé, 1936.

PIAGET, J. LA CONSTRUCTION DU RÉEL CHEZ L'ENFANT. Neuchâtel: Delachaux et Niestlé, 1937.

PiAget, J. Biologie et connaissance. Paris: Delachaux et Niestlé, 1992. 
SAUSSURE, F. Mémoire sur le système primitif des voyelles dans les langues indo-européennes. In: BALLY, Ch.; GAUTHIER, L. (org). RECUEIL DES PUBLICATIONS SCIENTIFIQUES de FERDINAND DE SAUSSURE. Genebra: Sonor, 1922. [edição original: 1879].

SAUSSURE, F. CoURS DE LINGUISTIQUE GÉNÉRALE. Paris: Payot, 1975. [edição original: 1916].

SAUSSURE, F. ECRITS DE LINGUISTIQUe GÉNÉRALE. Paris: Gallimard, 2002.

SCHNEUWLY, B. LE LANGAGE ÉCRIT CHEZ L'ENFANT: la production des textes informatifs et argumentatifs. Paris: Delachaux et Niestlé, 1988.

TURPIN, B. “La légende de Sigfrid et l'histoire burgonde”. CAHIERS DE L'HERNESAUSSURE, [S.I.], n. 76, p. 351-429, 2003.

VYGOTSKI, L.S. PENSÉE ET LANGAGE. Paris: La Dispute, 1997. [edição original: 1934].

Recebido em: OUTUBRO de 2011

Aprovado em: NOVEMBRO de 2011 